\title{
Fabrication and Micropatterning of a Hybrid Composite of Amorphous Calcium Carbonate and Poly(ethylenimine)
}

\author{
Hyun Sook Lee, Tai Hwan Ha, ${ }^{\dagger}$ Hyun Min Kim, and Kwan Kim \\ Department of Chemistry, Seoul National Lniversity, Seoul 151-7+2, Korea. E-mail: kwankimasnackr \\ BioNanotechnologv Research Center, Korea Research Institute of Bioscience and Biotechnologn, Daejeon 305-333, Korea \\ Received October 9, 2006
}

\begin{abstract}
Amorphous calcium carbonate ( $\mathrm{ACC}$ ) can readily be prepared using ethanol as the reaction medium and ammonium carbonate as the source of carbon dioxide. Other additives. or any elaborate $\mathrm{pH}$ control are not needed to form the initial calcium carbonate precipitate. Ammonia generated from ammonium carbonate maintains the reaction medium in a neutral or weakly basic condition. retarding the crystallization of $\mathrm{ACC}$. while ethanol itself inhibits the dissolution of ACC. The ACC prepared in this way provides a rare opportunity to fabricate molded biomimetic cry stals in witro. but the $\mathrm{ACC}$ is too fragile to be fabricated into proper shapes. The malleability of ACC is however greatly enhanced by incorporating poly (ethỵlenimine) (PEI). The ACCl PEI composite can then be fabricated. using a proper mold or template. into mechanically durable biomimetic crystals of definite shape. The ACC in the ACC/PEI composite can further be transformed into vaterite by heating under $\mathrm{N}_{2}$ atmosphere. while the native $\mathrm{ACC}$ simply comverts into calcite.
\end{abstract}

Key Words: Amorphous calcium carbonate. Biomimetic crystal, Poly(ethyleninuine). Biological hybrid conposite, Micropatterning

\section{Introduction}

Natural organisms that produce biological composites exert exquisite control over the minerals they deposit. creating materials of myriad shapes and sizes that are often of high strength. ${ }^{\text {l }}$ Mineralized tissues are often found to contain polymorphs and individual minerals whose crystal morphology size and orientation are determined by local conditions and. in particular the presence of matrix proteins or other macromolecules.: The processes and materials that control such crystal nucleation and growth are of great interest to materials scientists who seek to manufacture composite materials and crystalline forms analogous to those produced by nature.

Calcium carbonate is one of the most abundant biominerals and can also be grown easily under laboratory conditions. It is well known that three polymorphic forms of calcium carbonate exist. i.e. vaterite. calcite and aragonite. with each polymorph able to adopt a number of morphologies. Which polymorph is formed and with which particular morphology, is controlled both thermodynamically and kinetically. ${ }^{3}$ In addition to the stable polymorphs. amorphous calcium carbonate (ACC) also exists. Various organisms store their calcium and carbonate temporarily in the form of $\mathrm{ACC}^{4}$ This can occur because $\mathrm{ACC}$ is unstable and easily dissolves in water. ${ }^{5}$ Once formed in vitro pure $\mathrm{ACC}$ rapidly transforms into diverse crystalline forms. The micropatterned three-dimensional ACC phase prepared on a disordered phosphate- methyl- or hydroxỵl-terminated monolayers turns into a calcite phase. ${ }^{\text {td }}$ ACC sy'nthesized by the generation of carbon dioxide from dialkyl carbonate in aqueous calcium chloride solution is transformed into vaterite by addition of a PMAA block-copolymer. It has been known that polymers containing a number of ester groups in either the polymer backbone or side chains ${ }^{7}$ or phosphorus-containing poly(ethylene glycol) $^{8}$ and poly(propylenimine) dendrimers ${ }^{9}$ inhibit the formation of nuclei of a crystalline polymorph from the metastable ACC phase. In addition, an anionic polymer can serve as a process-directing agent which induces liquid-liquid phase separation and ultimately deposition of amorphous precursor film under a supersaturated solution of calcium carbonate. ${ }^{1 /}$ Stabilized ACC also forms in nature solely for structural purposes. " Stabilization of ACC in that case is achieved by the cooperative action of magnesium ions and glycoproteins that are rich in glutamic and hydroxyamino acids. ${ }^{4(a) .+(i c) .12}$

As the above discussion implies biominerals in living organisms usually grow inside organic frameworks that can confine the occurrence of mineral deposition to specific sites with predetermined patterns. Hence oriented crystals with diverse morphologies can be formed starting from nucleation at well-defined and chemically modified intracellular sites. Despite attempting to mimic living organisms, the growth of crystals with designed morphologies in vitro is still at a very primitive and immature stage however. ${ }^{13}$ In the orthopedic field (i.e. guided bone generation), for example. natural and synthetic materials are used as gap fillers for bone defect. The filling materials are eventually reabsorbed during bone in-growth (e.g. calcium phosphate and hydroxyapatite) provoked by cellular osteogenesis. Recently, calcium carbonate has been attracting as a gap filler possessing high

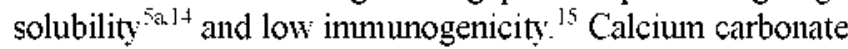
is superior to other biomaterials such as coral. collagen. calcium phosphate, and polytetrafluoroethylene (PTFE) in view of the in-growth rate. the inmunogenicity. and the mechanical strength of grown bones. ${ }^{15 b .16}$ The use of ACC 
would then be desired since it is isotropic and thus can sustain mechanical strain from all directions such that it could be molded into diverse morphologies: ${ }^{+d, 17}$ ACC has also even higher solubility' in physiological conditions.

Recently, we discovered that ACC could readily be prepared using ethanol as the reaction medium and ammonium carbonate as the source of carbon dioxide.$^{18}$ No other additives. nor any elaborate $\mathrm{pH}$ control were needed to form the initial calcium carbonate precipitate (CCP). The ammonia generated from ammonium carbonate. as well as the ethanol. was crucial. not only for the formation and stabilization of CCP. but also for its subsequent conversion to $\mathrm{ACC}$ by gentle heating or just keeping the $\mathrm{CCP}$ in ethanol. The ACC prepared in this way provided a rare opportunity to examine the feasibility of fabrication of molded biomimetic crystals resembling an implanted template usable in repairing bone defects. Unfortunately however. the ACC was so fragile that even a two-dimensional pattern fabricated using the material was not secure. We thus devised an altemative route to synthesize stable composites composed of ACC and poly(ethylenimine) (PEI) which in fact can be assembled into robust 2-D pattems and architectures. Herein. we report a novel sy'nthetic method to prepare those hybrid composites. and demonstrate their flexibility in forming a variety of molded calcium carbonate shapes. The transformation of $\mathrm{ACC}$ in the composite into more ordered crystalline phases at elevated temperatures is also demonstrated.

\section{Experimental}

The precursor of $\mathrm{ACC}$ was first grown in $10 \mathrm{mM}$ ethanolic $\mathrm{CaCl}_{2}$ solution that also contained a certain amount of PEI (average $\mathrm{MW}=750000.3 \mathrm{mg} / \mathrm{mL}$ ). by allowing the diffusion of $\mathrm{CO}_{2}$ vapor from $\left(\mathrm{NH}_{4}\right)_{2} \mathrm{CO}_{3}$ into the solution. ${ }^{19}$ As the reaction proceeded the solution phase became milkywhite. and it was maintained in that way for up to 12 hrs until centrifugation: in the absence of PEI, a white precipitate was deposited at the bottom. however. The jelly'-like precipitate was centrifuged at $1000 \mathrm{mpm}$. and then stored in ethanol after washing twice with the same solvent. The resulting 'fluidic calcium carbonate precipitate (CCP)' was subsequently used in micropatterning perfonmed with an elastomeric poly(dimethylsiloxane) (PDMS) stamp. The micro molding process and the micro imprinting process adopted in this work are schematically drawn in Scheme 1.

In the micro molding process. a PDMS stamp with regular stripe pattems was laid on a silicon substrate to form microsized channels. and then a few hundred micro liters of asprepared 'fluidic CCP' was dropped at the entrance site of the channel to flow inside by capillary action. In the micro imprinting process. aliquots of concentrated 'fluidic CCP' were spread on a PDMS stamp. and were left to dry for 6 hrs under ambient conditions or gently heated to $80^{\circ} \mathrm{C}$ in an oven: concentrated ' $\mathrm{CCP}$ ' was obtained by discarding the ethanol supenatant after storing the as-prepared ' $\mathrm{CCP}$ ' in a stationary state for 2 hrs. The shaped calcium carbonate layer was stripped off using double-sided adhesive carbon

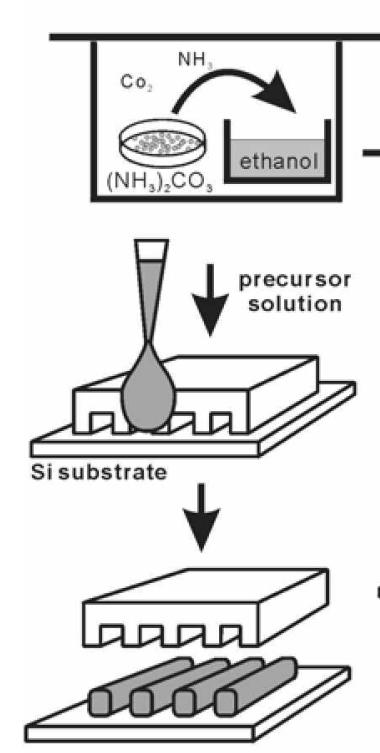

(a)
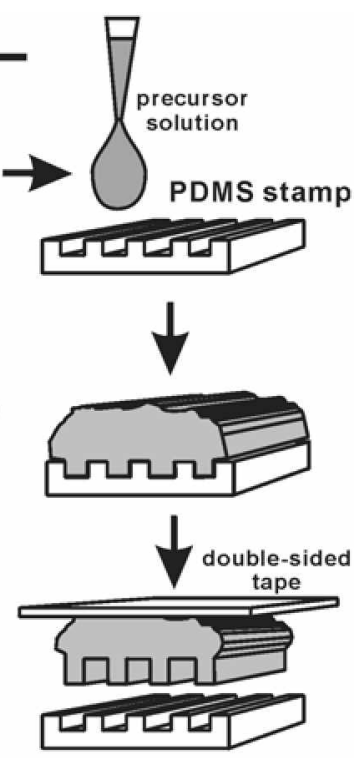

(b)
Scheme 1. Schematic diagrams of micropattening protocols; (a) micro molding process and (b) micro imprinting process. See text.

tape.

The structural analyses of the dried CCP were carried out by FT-IR spectroscopy (Bruker IFS 113v FT-IR spectrometer). X-ray diffractometry (XRD. Rigaku Model D/Max3C) and temperature-dependent X-ray diffractometry (Bruker GADDS). More specifically. the infrared spectra of the powdered samples were obtained using diffuse reflectance optics (Harrick Model DRA-2CO) ${ }^{\text {.11 }}$ The morphology of the patterned calcium carbonate was observed using a field emission scanuing electron microscope (FE-SEM, JEOL JSM-6700F) and an atomic force microscope (AFM. Digital Instruments Nanoscope IIIa). Themogravimetric analysis (TGA) of CCP was conducted with a TA Instrument 2050 thermogravimetric analyzer in a $\mathrm{N}_{2}$ atmosphere flowing at $110 \mathrm{~mL} / \mathrm{min}$. with a heating rate of $10^{\circ} \mathrm{C} / \mathrm{min}$.

\section{Results and Discussion}

A series of different amounts of poly (etlyylenimine) (PEI) were added into the reaction vessel of ethanolic $\mathrm{CaCl}_{2}$ solution to obtain the calcium carbonate precipitate (CCP), as mentioned in the Experimental section. The necessary carbon dioxide was obtained from the sublimation of ammonium carbonate. The formation of CCP was seen to accelerate in the presence of PEI compared to the case without PEI. This can be understood on the grounds that PEI solution is already basic. while in its absence the reaction medium becomes basic after ammonia is diffused into the medium by the sublimation of anmonium carbonate.

The CCP was confirmed to be a composite of ACC and PEI. from XRD and FT-IR spectroscopy. As can be seen in Figure 1(a), the XRD pattern is silent and featureless. indicative of the amorphous nature of the CCP: for comparison. the XRD pattern for authentic calcite that has been grown in 

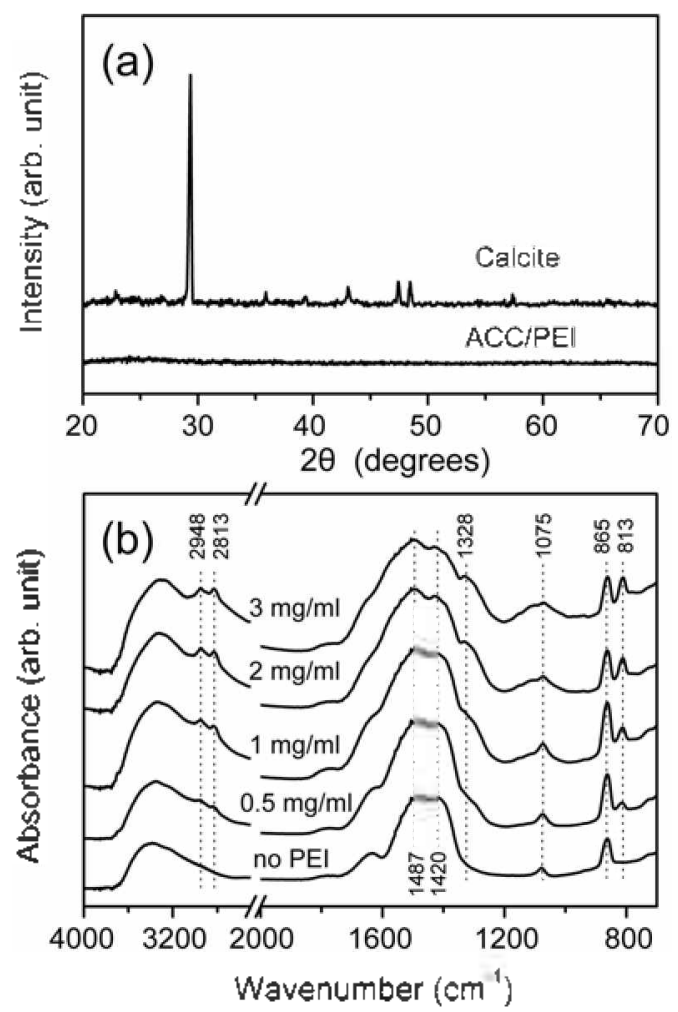

Figure 1. (a) XRD patterns of $\mathrm{CCP}$ and authentic calcite, (b) mifrared spectra of CCP prepared at diverse concentration of $\mathrm{PEI}$.

water is also shown in Figure I(a). On the other hand. the presence of the ACC phase is characterized. in the infrared spectra shown in Figure 1(b). by the antisymmetric stretching $\left(v_{s}\right)$ bands of the carbonate ions that are split at 1420 and $1487 \mathrm{~cm}^{-1}$ due to the lack of environmental symmetry. ${ }^{+(a)>11}$ The band at $1075 \mathrm{~cm}^{-1}$ can be assigned to the symmetric stretching mode $\left(v_{l}\right)$ of the carbonate ion. and its broad features are also attributed to the absence of symmetry.t(a), 1 The carbonate out-of-plane bending ( $v$ ) band at $865 \mathrm{~cm}^{-1}$ is also broader than its counter band in the crystalline phase (data not shown). Incorporation of PEI is clear from the presence of the $\mathrm{CH}_{2}$ stretching bands at 2948 and $2813 \mathrm{~cm}^{-1}$. which become intensified as the content of PEI increases. In addition. a shoulder peak at $1328 \mathrm{~cm}^{-1}$. as well as a broad peak at $\sim 1100 \mathrm{~cm}^{-1}$. is also attributed to PEI. 2 .

In Figure l(b). there is an intriguing band at $813 \mathrm{~cm}^{-1}$ which becomes more intense as the amount of PEI increases. In our previous work, a similar band was identified. albeit weak, at $\sim 820 \mathrm{~cm}^{-1}$. and the band was attributed to out-ofplane bending of the carbonate that was under interaction with ammonia. ${ }^{18}$ Upon heating gently to $-100^{\circ} \mathrm{C}$ to obtain pure $\mathrm{ACC}$ from the $\mathrm{CCP}$, the band conpletely disappeared. however. owing to the vaporization of the ammonia (vide infra). The band observed herein at $813 \mathrm{~cm}^{-1}$ for the $\mathrm{ACC} /$ $\mathrm{PEI}$ conposite can also be attributed to out-of-plane bending of the carbonate that is now under interaction with the amine group of PEI

Conventional $\mathrm{ACC}$ is known to transform rapidly into the more stable crystalline polymorph of calcium carbonate. ${ }^{4 c, 7}$

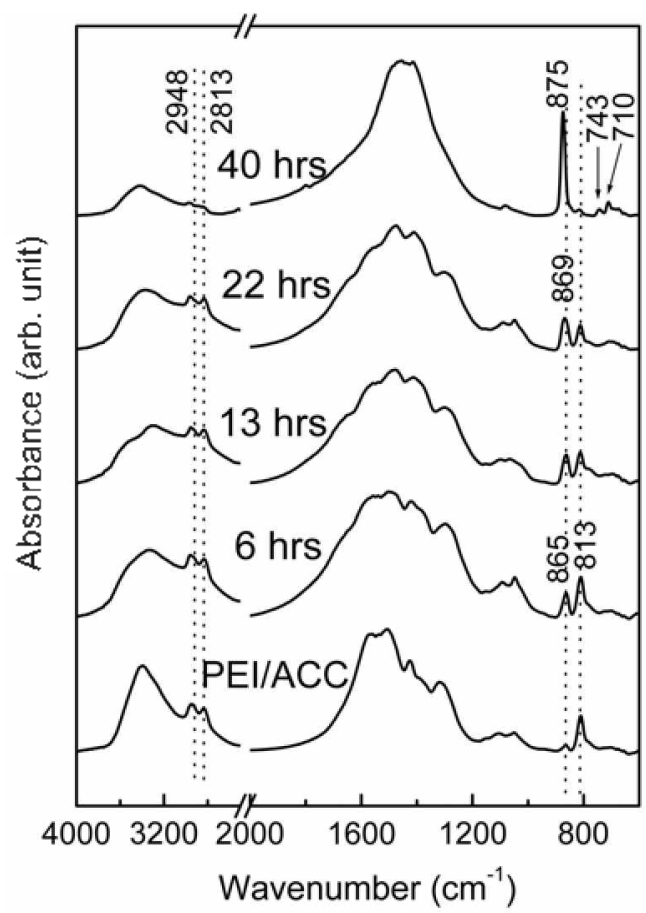

Figure 2. Intrared spectra of ACC/PEI composite taken ater soaking in water for a certain period of time and then dried.

We have reported that the anmonia-stabilized ACC converts to calcite in a week at ambient conditions of $40-60 \%$ relative humidity. ${ }^{18}$ The ACC/PEI composite prepared in this work is hardly subjected to transformation into calcite. at least not for 2 months. The enhanced stability is attributed to the polymeric nature of PEI with extremely low vapor pressure compared to the ammonia incorporated in simple CC.Ps (vide supra). The presence of amine groups in the coordination sphere around the calcium and/or carbonate ions is supposed to prevent its reorganization into stable crystalline phases. When the ACC/PEI composite is soaked in water. PEI gradually dissolves out. however, allowing the formation of crystalline calcium carbonates. As shown in Figure 2, the $\mathrm{CH}_{2}$ stretching bands at $2800-2900 \mathrm{~cm}^{-1}$ (due to the PEI backbone) and the out-of-plane bending band of carbonate at $813 \mathrm{~cm}^{-1}$ (under interaction with amine groups) are weakened. while the carbonate bending band at $875 \mathrm{~cm}^{-1}$, indicative of the fomation of crystalline phases. grows upon soaking in water: after soaking in water for $40 \mathrm{hrs}$. the characteristic infrared peaks of vaterite and calcite appear distinctly at 743 and $710 \mathrm{~cm}^{-1}$. respectively.

The polymeric network of PEI also affects the thermal characteristics of ACC. As shown in Figure 3(a), the simple ACC made in ethanol undergoes two drastic changes in the thermo-gravimetric analysis. The one corresponds to a continuous loss of water below $200^{\circ} \mathrm{C}$ and the other corresponds to the transition from calcite to calcium oxide. along with the loss of carbon dioxide. As can be seen in a DSC data (see the inset of Figure 3(a)). the transition from ACC to calcite occurs at $-350^{\circ} \mathrm{C}$. This transformation was further confinmed by variable temperature $\mathrm{XRD}$ experiment, showing calcite peaks near $-340^{\circ} \mathrm{C}$ (Figure $3(\mathrm{~b})$ ). In the case 

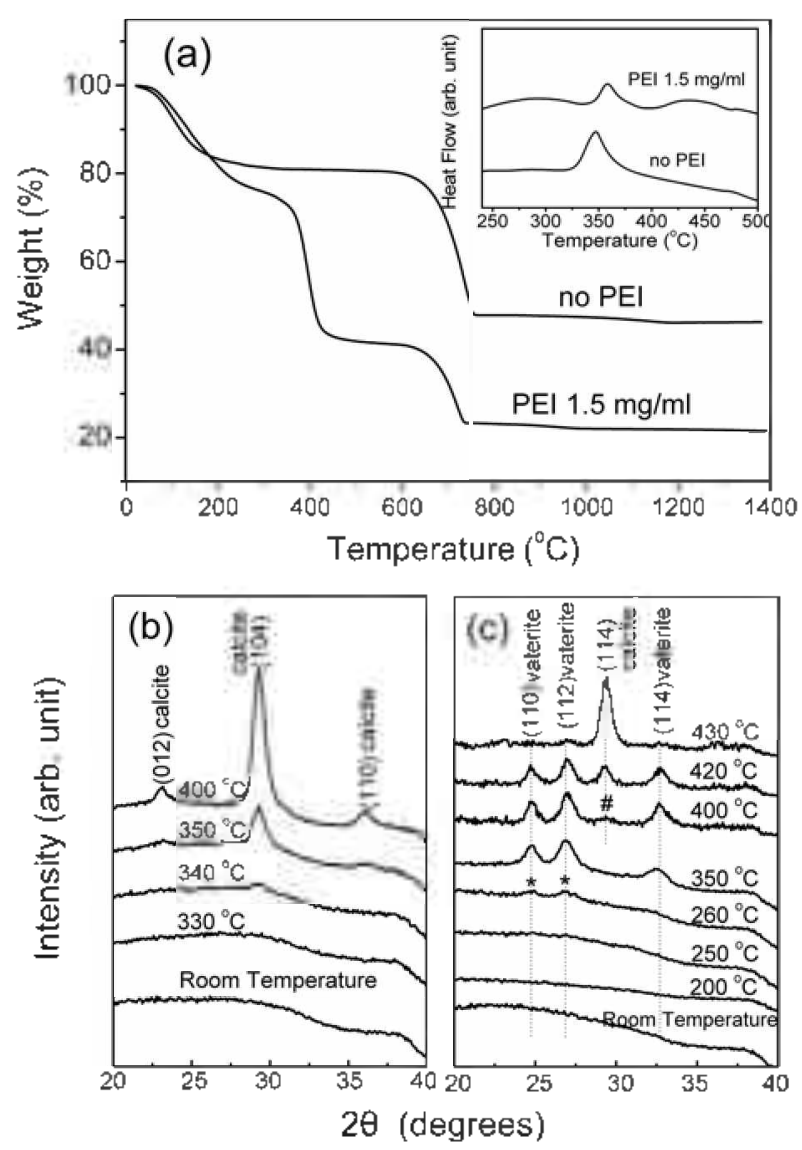

Figure 3. (a) TGA and DSC analyses of the simple ACC and the $A C C / P E l$ composite, and temperature-dependent $\mathrm{XKD}$ pattents of (b) the simple ACC and (c) the ACC/PEl composite.

of $\mathrm{ACC} / \mathrm{PEI}$ composite, an additional gravimetric loss occurs around $400^{\circ} \mathrm{C}$ due to the thermal decomposition of the incorporated PEI. The presence of an exothermic peak at $\sim 360^{\circ} \mathrm{C}$ in the DSC data for both the simple ACC and the $\mathrm{ACC} / \mathrm{PEI}$ composite suggests. however, that PEI affects little the thermal stability of the ACC phase. Interestingly a more careful examination reveals that the presence of PEI accelerates a phase transformation of $\mathrm{ACC}$. As can be seen in Figure 3(c), the temperature-dependent XRD data clearly indicates that $\mathrm{ACC}$ is converted to vaterite at $\sim 260^{\circ} \mathrm{C}$. while calcites are forming at $-400^{\circ} \mathrm{C}$ where PEI is subjected to decompose. In fact. vaterite is known to form when heating an ACC composite with poly'( $\varepsilon$-caprolactone) or poly(methyl methacrylate). ${ }^{7}$ The anine groups in PEI may similarly trigger the formation of vaterite for the $\mathrm{ACC} / \mathrm{PEI}$ composite.

For a comparative purpose. a composite of $\mathrm{ACC}$ with poly'(ethylene glycol) (PEG) or poly (acrylic acid) (PAA) was also prepared by replacing PEI with PEG (average MW $=3400.3 \mathrm{mg} / \mathrm{mL}$ ) or PAA (average $\mathrm{MW}=750000.3 \mathrm{mg} /$ $\mathrm{mL}$ ) in the reaction medium. Even when PEG was used instead of PEI. ACC was formed. but the ACC phase was present to be completely isolated from PEG The themal characteristics of the product were hardly different from those of the authentic ACC. In contrast. when PAA was used instead of PEI. a composite of ACC incorporating PAA
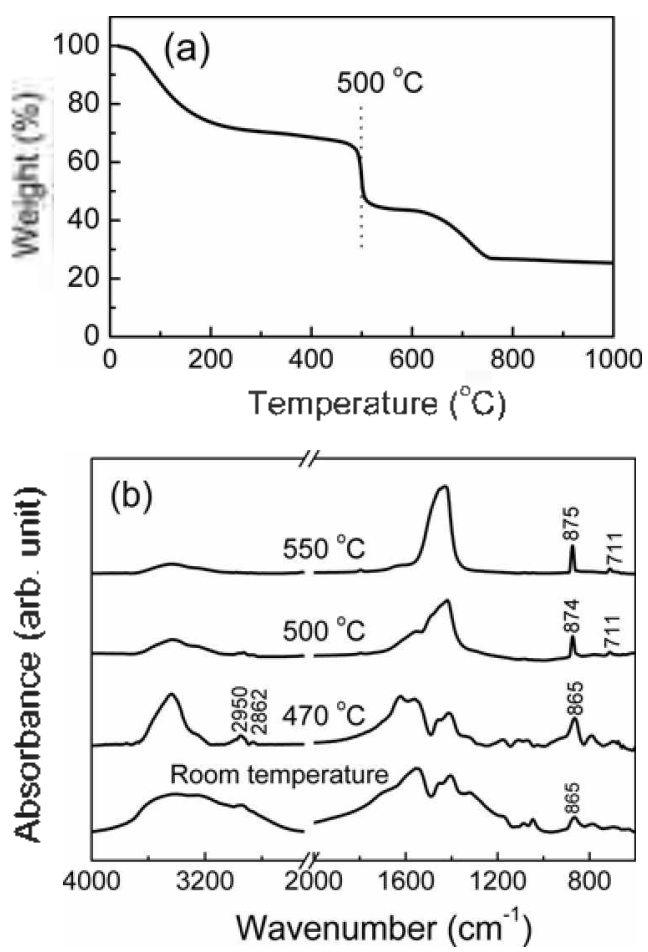

Figure 4. (a) TGA analysis and (b) infrared spectra of the ACC/ PAA composite heated to 470,500 , and $550^{\circ} \mathrm{C}$.

(called ACC/PAA) was fonmed exhibiting enhanced thenmal stability: As shown in Figure 4(a), the ACC/PAA composite undergoes three drastic changes in the thermo-gravinetric analy sis. The first gravimetric loss corresponds to a continuous loss of water below $200^{\circ} \mathrm{C}$ and the second occurs around $500^{\circ} \mathrm{C}$ due to the thermal decomposition of the incorporated PAA. Another corresponds to the transition from calcite to calcium oxide along with the loss of carbon dioxide. The ACC phase coordinated with PAA sustains the amorphous characteristics up to $470^{\circ} \mathrm{C}$ that can be inferred from the out-of-plane bending mode of carbonate at $865 \mathrm{~cm}^{-1}$ of ACC. At $500^{\circ} \mathrm{C}$, near the decomposition point of PAA, the bands of PAA at $\sim 2900.1670 .1320 \mathrm{~cm}^{-1}$ disappear. while the bands associated with calcite develop at 875 and $711 \mathrm{~cm}^{-1}$.

It is very intriguing that the phase transfomation of $\mathrm{ACC}$ into vaterite is highly dependent on the kind of polymers incorporated into the composite. For pure ACC. the transition occurs at $350^{\circ} \mathrm{C}$. but PEI once incorporated accelerates the transition to occur at $-260^{\circ} \mathrm{C}$. while PAA retards the transition to occur at $-470^{\circ} \mathrm{C}$. The higher thermal stability of the ACC/PAA composite is attributed to the coordination of the carboxyl groups of PAA with the calcium ions of ACC. For the case of the ACC/PEI composite positively charged amine groups of PEI are thought to interact more favorably with the negatively charged carboxylate groups of vaterite than ACC at elevated temperatures. ${ }^{2 / 2}$ In a similar fashion to the usual biogenic inorganic materials, the present $\mathrm{ACC} / \mathrm{PEI}$ composite may then be used in the fabrication of molded structures that will show high mechanical strength. The characteristics of the amorphous phase must be advantageous in building up biomimetic architectures since there is no 

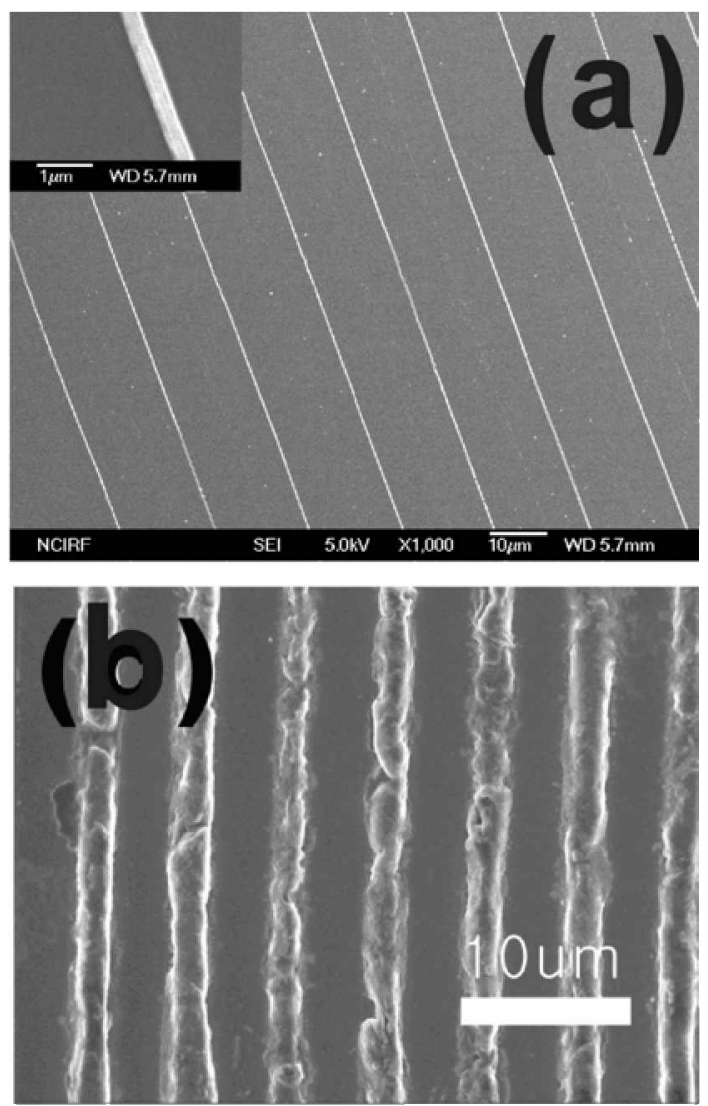

Figure 5. FE-SEM images of the micro-pattented ACC on a silicon wafer wio micro molding method using (a) the ACC/PEI composite and (b) the simple ACC.

preference in orientation.

As mentioned in the Experimental section. micropatterning was conducted using two protocols. ${ }^{2-4}$ one via a micro molding process and the other via a micro imprinting process (see also Scheme 1). Figure 5(a) shows the FE-SEM image of the ACC that has been patterned on a silicon substrate via the micro molding method: in this specific case a drop of the as-prepared CCP solution was introduced at the entrance of the micro-channel $[15 \times 5$ (width $\times$ height) $\left.\mu \mathrm{m}^{3}\right]$ formed by the contact of PDMS stamp with a silicon wafer. After one hour incubation at ambient condition. the PDMS stamp was carefully removed and the remaining wafer was further kept in an anhydrous chamber for three hours. Relatively sharp lines of $\sim 400 \mathrm{~nm}$ width are observed in the FE-SEM image as shown in Figure 5(a). The height is measured to be $350-500 \mathrm{~nm}$ in the AFM measurement. which is far smaller than the actual depth of the PDMS stamp. i.e. $3 \mu \mathrm{m}$, however. Supposedly, this was because the as-prepared CCP solution was too dilute to be drawn into the channel rapidly by the capillary force ${ }^{3}$ When micro-patterning is conducted using ethanolic CCP without PEI. very uneven and irregular patterns are produced. as shown in Figure 5(b). Local coagulation of CCP seems to take place during the evaporation of ethanol. A fairly even pattern obtainable in the presence of PEI may then be attributed to the retardation of solvent evaporation associated with the
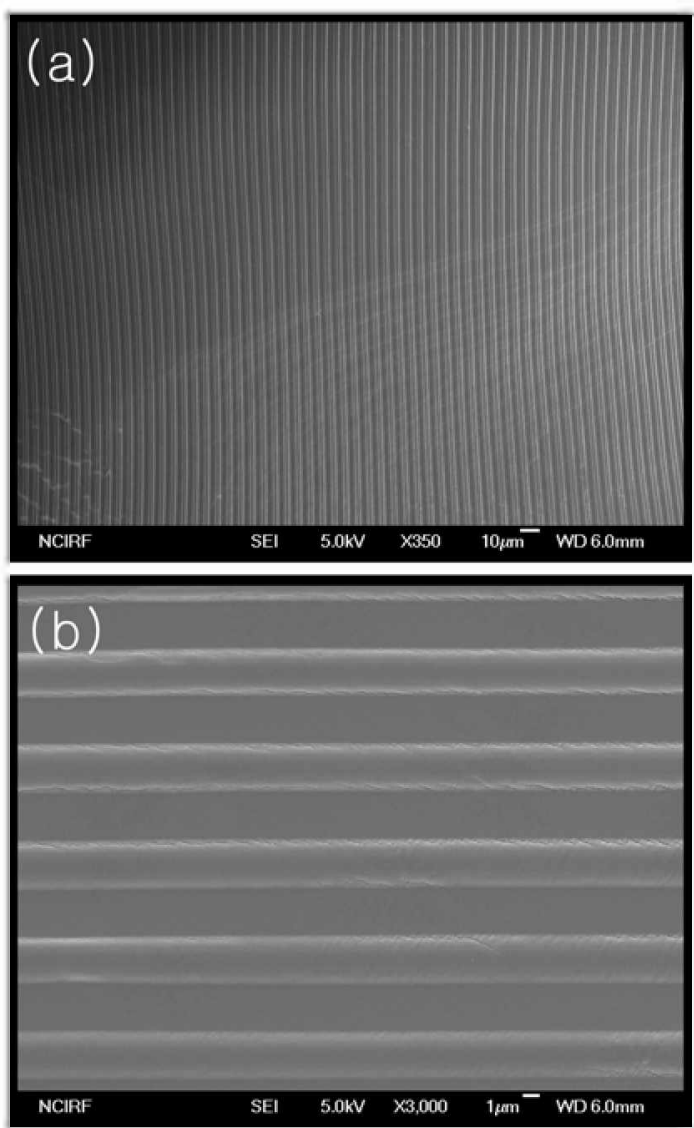

Figure 6. FE-SEM images of the ACC/PEI composite that has been fabricated wia micro imprinting process, shown with different magnifications.

hygroscopic nature of PEI.

Figure 6 shows the FE-SEM images of ACC aggregates (with different magnification) that have been fabricated via the micro imprinting process. Regularly spaced and defectfree parallel line structures are seen over large areas (i.e. $300 \mathrm{\mu m} \times 300 \mathrm{\mu m}$ ) in Figure 6(a): the image is the negative replica of the PDMS stamp employed initially. The magnified image in Figure 6(b) reveals that the surface is. in fact. very smooth and continuous: a very homogeneous pattem can be obtained even on a millimeter scale. As mentioned in the Introduction, the imprinting method cannot be applied using the CCP without PEI: as the solvent evaporates. the gel-like CCP tuns into ACC in powdered state. Owing to the excessive stability of the ACC/PEI. the patterned structure in Figure 6 remains in a stable state without converting to calcite for at least 2 months.

In conclusion. it is evident that the stability and malleability of ACC are greatly enhanced upon the incorporation of PEI. When heated under $N_{2}$ atmosphere. the ACC in the $\mathrm{ACC} / \mathrm{PEl}$ composite transforms into vaterite, while the native ACC simply converts into calcite. Since the precursor phase formed in ethanol is fluidic and gel-like. the composite can be easily fabricated into any shape as required by a template in clinical implants. The prospects for application of the present ACC/PEI composite are thus expected to be very high. 
Acknowledgement. This work was supported by the Ministry of Commerce. Industry and Energy of the Republic of Korea (Nano Project. M10213240001-02B1524-00210).

\section{References}

1. (a) Biomineralization: Chentical and Biochemical Perspectives: Mann. S.: Webb. J.: Williams. R. J. P.. Eds.: VCH Publishers: Weinheim. 1989. (b) Lowenstam. H. A.: Weiner. S. On Bionmeralization: Oxford University Press: Oxford. 1989

2. (a) Benman. A.: Addadi. L.: Weiner S. Nature 1988. 331, 546 (b) Falini. G.: Albeck. S: Weiner, S.: Addadi, L. Scrence 1996 271. 67. (c) Kato. T.: Sugawara. A.: Hosoda. N. Adr: Mater. 2002. IH. 869 and references therein.

3. (a) Colten. H.: Mann. S. Angew: Chent. Int. Ed 2003. 42.2350. (b) Dickinson, S. R.: MeGrath, K. M. J. Whater. Chem. 2003, 13 . 928. (c) Spanos. N.: Koutsoukos, P. G. J. Phys. Chem. B 1998. 102,6679. (d) Jannieson. J. C. J. Chem. Phns. 1953,21.1385.

4. (a) Aizenberg. J.: Lambert. G.: Weiner. S.: Addadi. L. J. Am. Chem. Soc. 2002. 124. 32. (b) Weiss. I. M.: Tuross. N.: Addadi. L.: Weiner. S. J. Exp. Zool. 2002. 293. 478. (c) Addadi. L.: Raz. S.: Weiner S. Ad Mater 2003, 15,959. (d) Aizenberg. I.: Muller. D. A.: Grazul. I. L.: Hamann, D. R. Scrence 2003, 299.1205.

5. (a) Brečevic. L.: Nielsen. A. E. J. Chyst. Growth 1989. 98, 304. (b) Ogino. T: Suzuki. T.: Sawada. K. Geochim Cosmochim .Ac. 1987. 51. 2757. (c) Gal. J. Y.: Bollinger. J. C.: Tolosa. H.: Gache. N. Talanta 1996. 43, 1497

6. Faatz, M.: Gröhn, F. Wegner. G. Materials Science and Engineering $C$ 2005, 25, 153 .

7. Han. I. T.: Xu, X.: Kim. D. H.: Cho, K. Chem. Water 2005, 17. 136.

8. Merten. H. L.: Bachman. G. L. US. Patent 1,237. It7. 1980.

9. Donners. J. J. J. M.: Heywood. B. R.: Meijer. E. W.: Nolte. R. J. M.: Roman. C.: Schenning. A. P. H. J.: Sommerdijk. N. A. J. M. Chem. Conmmi 2000. 1937.

10. (a) Volkmer. D: Harms, M.: Gower. L.: Ziegler A. Angew: Chem. Iht. Ed. 2005, 4t. 639. (b) Gower. L. B.: Odom. D. J. J. Const. Growth 2000. 210.719.

11. Prenant. M. Biol. Rev: 1927. 2.365.

12. Raz. S.: Weiner. S.: Addadi. L. Att: hater 2000. 12. 38.

13. (a) Sugawara. A.: Islivi, T: Kato. T. Angew: Chem. Wht. Ed. 2003.
42. 5299. (b) Rautaray. D.: Ahmad, A.: Sastry, M. J. Am. Chem Soc. 2003. 125.14656 .

14. (a) Heughebaert. J. C.: Nancollas. G. H. J. Phws Chem. 1984. 88. 2478. (b) Braye. F.: Irigaray. I. L.: Tallot. E.: Oudadesse. H.: Weber. G. Deschamps. N. Bionaterials 1990. 11,83 .

15. (a) Maeda. H.: Kasuga. T.: Hench. L. L. Bionaterials 2006, 27. 1216. (b) Combes. C.; Mia, B; Bareille, R, Rey. C. Bionaterials 2006. 27. 1945.

16. (a) Chiroff. R. I.: White. E. W.: Weber. I. N.: Roy. D. M. J. Bioned Mater Res. 1975. 9. 29. (b) Souyris, F.: Pellequer. C: Payrot. C. Servera. C. J. Maxillofac. Surg 1985, 13, 64. (c) Walsh, W. R: Chapman-Sheath, P. J; Cain. S.; Debes, J.: Bruce.

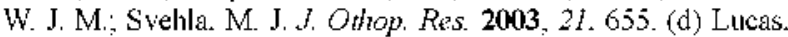
A.: Gaude. J.: Carel. C.: Michel. J. F.: Cathelineau. G. Int. J. Inorg. Mater 2001. 3. 87. (e) Blom. E. T.: Klein-Nulend. T.: Wolke. J. G C.: Van Waas. M. A. T.: Driessens. F. C. M.: Burger. E. H. J. Bioned Mater Res. 2002. 59.265. (f) Fontaine, M. L.: Combes. C.: Sillam, T.: Dechambre. G.; Rey, C. Key Eng. Haten 2005, 284. 105.

17. Loste. E.: Meldium. F. C. Chent Comm. 2001. 10.901.

18. Lee. H. S.: Ha. T. H.: Kim. K. Mater. Chent \& Phws 2005.93. 376.

19. Choi. J. S.: Choi, M. J.: Ko. K. S.: Rhee, B. D.: Pak. Y. K: Bang. I. S.: Lee, M. Bull. Korean Chem Soc, 2006, 27, 1335.

20. Shin, Y. W.: Kim. T. H.: Lee. K. Y.: Park, K, Han, S. W.: Lee, S S.: Kim. T. S.: Kiml. J. Bull Korean Chem. Soc. 2005. 26.473.

21. Aizenberg. J:: Lambert. G.: Addadi. L:: Weiner. S. Adh: Mater 1996. 8.222.

22. Ha. T. H.: Kim, D. K.: Choi. M.U.: Kim. K. J. Colloidal hnerface? Science 2000. 226, 98 .

23. (a) Chen, C. C.: Boskey, A. L. Cakif. Tisste Iht. 1985, 37. 395. (b) Mann. S.; Heywood, B. R.: Rajam. S.; Walker, J. B. A. ACS Stmp. Ser 1991. HH. 28. (c) Dont1ers. J. T. T. M.: Heywood. B. R.: Meijer. E. W.; Nolte, R. J. M.; Sommerdijk. N. A. J. M. Chem. Eur. J. 2002. 8. 2561 .

24. (a) Xia, Y; Whitesides, G. M. Angew: Chem Int. Ed 1998. 37. 550. (b) Martin. C. R: Aksay, I. A. J. Phus. Chem. B 2003, 107. 4261. (c) Ginzburg, M. MacLachlan. M. J.: Yang, S. M: Coombs. N.: Coyle. T. W.: Raju. N. P.: Greedan. J. E.: Herber. R. H.: Ozin. G. A.: Mantners. I. J. An. Chem. Soc. 2002. 12+. 2625.

25. (a) Kim. E.: Whitesides. G. M. J. Pho Chem. B 1997. 101. 855. (b) Mikalsen, E. A.; Payne. D. A. Solid State Ionics 2002, 151.53. 